\title{
PENGARUH ORIENTASI SELUBUNG BANGUNAN KACA GELAP TERHADAP BESARNYA PERPINDAHAN PANAS MATAHARI PADA GEDUNG SUKOWATI SEMARANG
}

\author{
Andarina Aji Pamurti, S.T. M.T. \\ Program Studi Perencanaan Wilayah dan Kota Fakultas Teknik Universitas Semarang; Jl. Soekarno Hatta, Tlogosari Kulon, \\ Kec. Pedurungan, Kota Semarang, Jawa Tengah 59160; andarina@usm.ac.id
}

Info Artikel:

Artikel Masuk: 15/02/2020

Artikel diterima: 07/03/2020

Tersedia Online: 30/03/2020

\begin{abstract}
ABSTRAK
Bangunan bergaya modern semakin berkembang di Indonesia, dengan gaya yang minimalis, simpel, mengusung keutamaaan fungsi bangunan serta terkesan mewah ini cocok dengan life style masyarakat perkotaan di Indonesia. Bangunan modern didominasi oleh penggunaan bahan - bahan pabriksasi, terutama kaca. Bahan pabriksasi ini apabila penggunaannya tidak tepat serta dengan desain arsitektur yang tidak memperhatikan iklim tropis lembab di Indonesia, mengakibatkan ketidaknyamanan penghuni. Hal tersebut meliputi penggunaan bahan pada selubung bangunan yang menyangkut mutu dan warna bahan serta desain sistem pembayangan baik berupa sun shading device maupun komposisi bangunan, disamping itu orientasi bangunan juga merupakan hal yang penting terhadap perolehan panas matahari. Studi dilakukan pada bangunan modern yaitu gedung Sukowati Semarang yang minim akan sun shading device dengan selubung bangunan yang didominasi oleh kaca, terutama pada facade timur dengan persentasi kaca $67 \%$ dan facade selatan dengan prosentasi kaca $55 \%$. Kaca yang digunakan adalah kaca berwarna gelap jenis panasap atau kaca warna. Hasil penelitian menunjukkan facade timur dan selatan memiliki nilai Overall Thermal Transfer Value (OTTV) adalah di atas standard 45 Watt / m2, maka terjadi ketidaknyamanan penghuni. Perpindahan panas matahari yang masuk ke dalam ruangan, salah satunya dipengaruhi oleh orientasi, Window to Wall Ratio (WWR), serta bahan bangunan. Kaca berwarna gelap memilki Shading Coefficient yang lebih rendah dibanding kaca bening, hijau atau biru. Namun kaca berwarna gelap pada Gedung Sukowati Semarang belum mengatasi permasalahan akan naungan panas matahari dikarenakan kurang tepatnya penggunaan jenis kaca.
\end{abstract}

Kata Kunci : Orientasi, Selubung Bangunan, Kaca Gelap, Perpindahan Panas Matahari

\begin{abstract}
Modern-style buildings are increasingly developing in Indonesia, with a minimalist style, simple, carrying the primacy of the function of the building and seemingly luxurious fit with the life style of urban communities in Indonesia. Modern buildings are dominated by the use of manufacturing materials, especially glass. This fabrication material if its use is inappropriate and with architectural designs that do not pay attention to the humid tropical climate in Indonesia, resulting in inconvenience of residents. This includes the use of materials in the building envelope which concerns the quality and color of the material as well as the design of the imagery system in the form of sun shading devices and the composition of the building, besides the orientation of the building is also important for the acquisition of solar heat. The study was conducted on a modern building, the Pertamina Sukowati Semarang building, which is minimal in terms of sun shading devices with glass-covered buildings, especially in the eastern facade with a glass percentage of $67 \%$ and a southern facade with a glass percentage of $55 \%$. The glass used is a dark colored type of heat glass or color glass. The results showed that the eastern and southern facades have an Overall Thermal Transfer Value (OTTV) value above the $45 \mathrm{Watt} / \mathrm{m} 2$ standard, hence occupant discomfort. Solar heat transfer into the room, one of which is influenced by orientation, Window to Wall Ratio (WWR), and building materials. Dark colored glass has a lower Shading Coefficient than clear glass, green or blue. But the dark tinted glass at the Pertamina Sukowati Semarang Building has not overcome the problem of solar thermal shade due to the inaccurate use of this type of glass.
\end{abstract}

Keyword: Orientation, Building Envelopes, Dark Glass, Solar Heat Transfer 


\section{PENDAHULUAN}

Banyak dijumpai bangunan modern di Indonesia mengusung desain dominan kaca dan minim sun shading supaya mengejar kesan minimalis dan simpel serta tanpa memperhatikan posisi orientasinya. Maka apabila desain tersebut diterapkan pada iklim Indonesia, maka panas matahari sangat mudah masuk ke dalam bangunan melalui fenestrasi kaca. Apabila ruangan menjadi panas, maka bangunan membutuhkan pengkondisian udara berupa Air Conditioning $(A C)$. Penggunaan freon pada AC yang berlebihan menyumbang peranan menipisnya ozon di bumi, yang dapat mengakibatkan buruknya kondisi udara, cuaca, dan iklim di bumi. Dan bangunan bergaya modern biasanya menggunakan $A C$ yang sangat besar, maka perlu desain arsitektur yang tepat dan penggunaan bahan yang tepat supaya mengurangi sumbangan penipisan ozon di bumi.

Salah satu gedung yang berasitektur modern adalah Gedung Sukowati, gedung ini berada di kawasan kampus Universitas Diponegoro Semarang, yaitu gedung kontribusi PT. Pertamina terhadap pendidikan di Universitas Diponegoro yang dipergunakan untuk kegiatan perkuliahan Teknik Geologi Universitas Diponegoro. Gedung ini bergaya modern yaitu terlihat dengan fasade yang minim akan ornamen dan penggunaan bahan fabrikasi yang didominasi oleh kaca berwarna gelap. Penggunaan kaca yang berwarna gelap adalah solusi terhadap penurunan perpindahan panas matahari yang masuk ke dalam ruangan pada bangunan modern di daerah tropis. Dibanding kaca bening atau kaca warna hijau dan biru, kaca berwarna gelap adalah paling rendah perpindahahan panas matahari terhadap ruangan (ASHRAE Fundamentals,1997 : 29). Facade yang didominasi oleh kaca adalah terutama facade timur dan facade selatan.

\section{DATA DAN METODE}

2.1. Data Facade Timur

Gedung yang memiliki facade yang berorientasi di timur ini, didominasi oleh penggunaan kaca Panasap berwarna abu - abu gelap dengan persentase kaca $67 \%$. Serta terdiri dari dinding masiv dengan finishing cat abu - abu muda dan putih serta batu candi namun minim akan penggunaan sun shading. Pada facade timur ini, menghubungkan dengan area komunal mahasiswa.

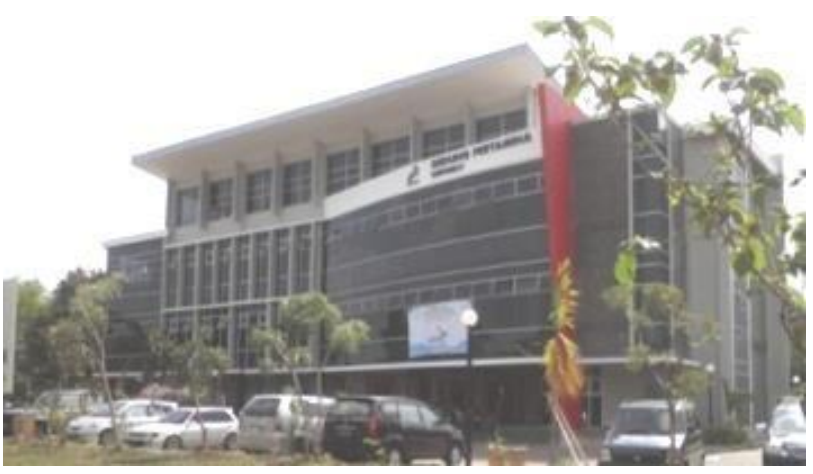

Gambar 1. Facade Timur Gedung Sukowati

Pada pagi hari saat jam perkuliahan, area komunal mahasiswa tersebut jarang dipergunakan oleh mahasiswa untuk berkumpul dikarenakan keadaan ruang yang kurang nyaman yakni suhu ruangan yang tinggi. Hal ini diakibatkan oleh tingginya intensitas radiasi matahari langsung dari arah timur di pagi hari yang menembus kaca menuju ruang komunal mahasiswa, sehingga ruangan menjadi panas dan silau.

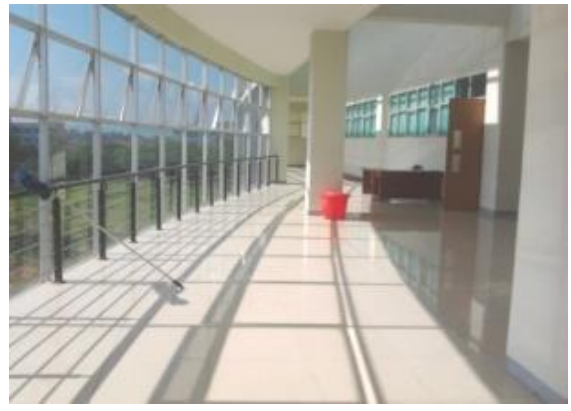

Gambar 2. Ruang Komunal Mahasiswa Orientasi Timur Pukul 08.30 
Pada facade timur memiliki tingkat pencahayaan alami 1432 lux ( skala 100 ) maka ruangan mendapat pencahayaan alami yang baik dan suhu ruangan pada facade ini yaitu 33 derajat celcius, maka ruangan terasa panas.

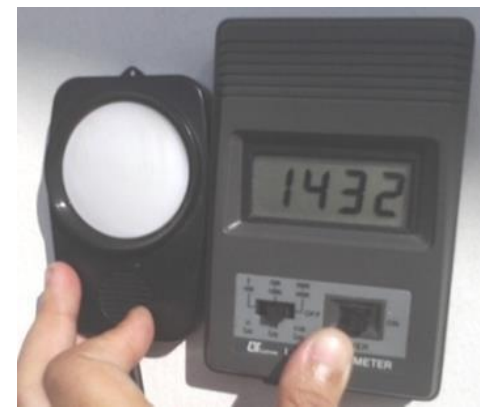

Gambar 3.

Nilai Pencahayaan

Alami Fasade Timur

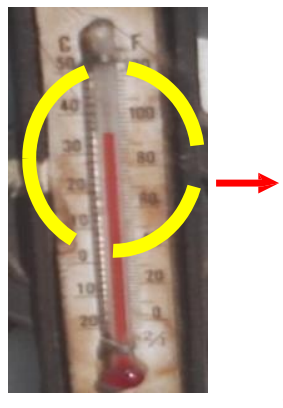

$33 \mathrm{C}$
Meskipun telah ditempuh solusi yang baik akan penurunan intensitas matahari langsung dengan penggunaan kaca yang berwarna gelap, namun pada kenyataannya hal ini belum juga menyelesaikan masalah yang seringkali dialami oleh bangunan modern di daerah tropis bila tidak disertai akan pelindungan akan matahari yakni sun shading device.

\subsection{Data Facade Selatan}

Pada orientasi selatan menghubungkan dengan ruang perkuliahan mahasiswa dan tangga gedung sisi selatan. Orientasi selatan memiliki facade yang terdiri dari dinding masiv dengan finishing cat abu - abu muda dan batu candi serta didominasi kaca abu - abu gelap yang tidak disertai sun shading device. Persentase kaca pada facade selatan yaitu $55 \%$.

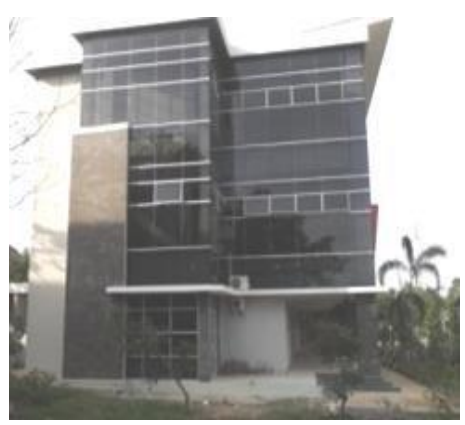

Gambar 5. Facade Selatan Gedung Sukowati
Dengan keadaan selubung bangunan tersebut di orientasi selatan, panas matahari cukup masuk ke dalam ruangan. Pada fasade selatan memiliki tingkat pencahayaan alami 81 lux ( skala 10 ) maka ruangan mendapat pencahayaan alami yang baik dan suhu ruangan pada fasade ini yaitu 29 derajat celcius, maka ruangan terasa panas.

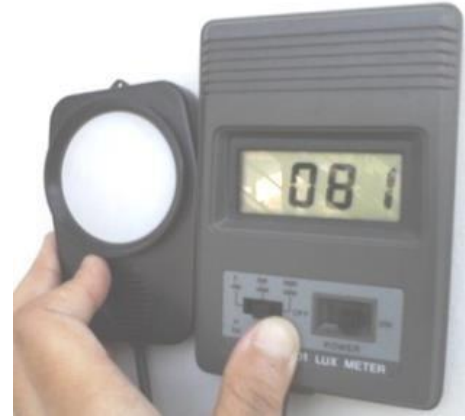

Gambar 6.

Pencahayaan

Facade Selatan

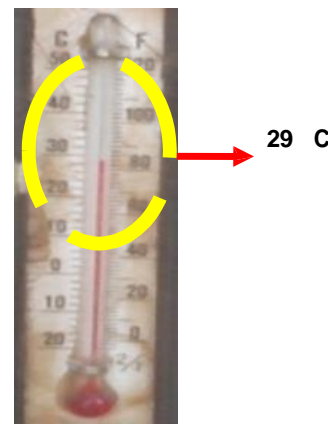

Gambar 7. Nilai Suhu Ruangan Alami Facade Selatan
Dengan keadaan selubung bangunan tersebut pada orientasi tertentu, sehingga mengakibatkan perpindahan panas matahari yang berbeda terhadap ruangan. Meskipun menggunakan bahan baik yaitu kaca gelap namun ruangan di Gedung Sukowati Semarang masih mendapatkan panas matahari yang besar sehingga ruangan mendapatkan suhu yang tinggi.

\subsection{Metode Penelitian}

Menggunakan data kuantitatif dan analisa kuantitatif. Analisa menggunakan rumus Overall Thermal Transfer Value ( OTTV ) berdasar Standard Nasional Indonesia.

Batasan Penelitian yaitu penelitian pada:

1. Overall Thermal Transfer Value ( OTTV ) untuk eksisting facade yang dominan kaca yaitu facade timur dan selatan serta apabila disimulasikan pada berbagai orientasi.

2. Overall Thermal Transfer Value ( OTTV) facade timur dan selatan disimulasikan apabila double skin dengan beton dihilangkan untuk berbagai orientasi.

3. Simulasi jenis kaca yang baik yaitu dengan nilai OTTV maksimal 45 Watt / m2 pada facade yang dominan kaca baik eksisting 
maupun apabila double skin dengan beton dihilangkan untuk berbagai orientasi.

Landasan teori yang digunakan untuk mengetahui perpindahan panas matahari pada gedung menggunakan rumus Overall Thermal Transfer Value ( OTTV ) berdasar Standard Nasional Indonesia

Transfer Value ( OTTV ) berdasar Standard Nasional Indonesia

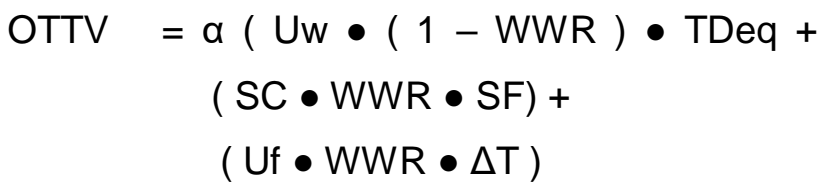

OTTV : nilai perpindahan termal menyelurruh pada dinding luar yang memiliki arah atau orientasi tertentu ( Watt / m2)

a : absorbtansi radiasi matahari

Uw : transmitansi termal dinding tak tembus cahaya ( Watt / m2.K)

WWR : perbandingan luas jendela dengan luas seluruh dinding luar pada orientasi yang ditentukan

TDEK : beda temperatur ekuivalen ( $\mathrm{K}$ )

SC : koeffisien peneduh dari system fenestrasi

SF : faktor radiasi matahari ( W/m2)

Uf : transmitansi termal fenestrasi

$(\mathrm{W} / \mathrm{m} 2 . \mathrm{K})$

$\Delta T \quad$ : beda temperatur perencanaan antara bagian luar dan bagian dalam ( diambil $5 \mathrm{~K}$ )

\section{HASIL DAN PEMBAHASAN}

\subsection{Facade Timur Disimulasikan Berbagai Orientasi}

Pada facade timur dengan rasio kaca $67 \%$, apabila disimulasikan ke berbagai orientasi maka Overall Thermal Transfer Value ( OTTV ) urutan dari terkecil ke terbesar adalah Selatan, Timur, Utara, Barat. Nilai OTTV untuk semua orientasi di atas standard $45 \mathrm{Watt} / \mathrm{m} 2$, maka ruangan cenderung panas.

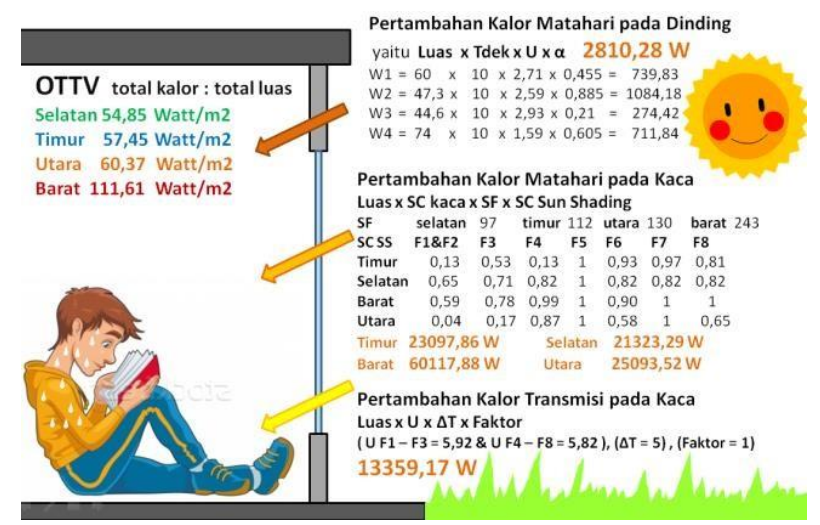

Gambar 8. OTTV Facade Timur bila Disimulasikan Berbagai Orientasi ( Sumber, 2012 )

Tabel di bawah adalah beberapa rekomendasi kaca yang tepat dengan nilai OTTV maksimal 45 watt / m2 yang dipengaruhi juga oleh faktor harga.

\begin{tabular}{|l|l|c|c|}
\hline \multicolumn{2}{|c|}{ Kaca } & $\begin{array}{c}\text { SC } \\
\text { maks }\end{array}$ & Jenis kaca \\
\hline Timur & Kaca single & 0,35 & Cool lite biru \\
\hline & Kaca double & 0,52 & Kaca warna hijau \\
\hline Selatan & Kaca single & 0,38 & Kaca reflektif gelap \\
\hline & Kaca double & 0,57 & Kaca warna biru \\
\hline Utara & Kaca single & 0,32 & Cool lite biru \\
\hline & Kaca double & 0,48 & Kaca warna hijau \\
\hline Barat & Kaca single & 0,16 & Cool lite silver \\
\hline & Kaca double & 0,2 & Cool lite silver \\
\hline
\end{tabular}

Tabel 1. Alternatif Jenis Kaca yang Tepat pada Fasade Timur untuk Berbagai Orientasi

\subsection{Facade Selatan Disimulasikan Berbagai Orientasi}

Pada facade selatan dengan rasio kaca $55 \%$, apabila disimulasikan ke berbagai orientasi maka Overall Thermal Transfer Value ( OTTV ) urutan dari terkecil ke terbesar adalah Selatan, Timur, Utara, Barat. Nilai OTTV untuk semua orientasi di atas standard $45 \mathrm{Watt} / \mathrm{m} 2$, maka ruangan cenderung panas. 


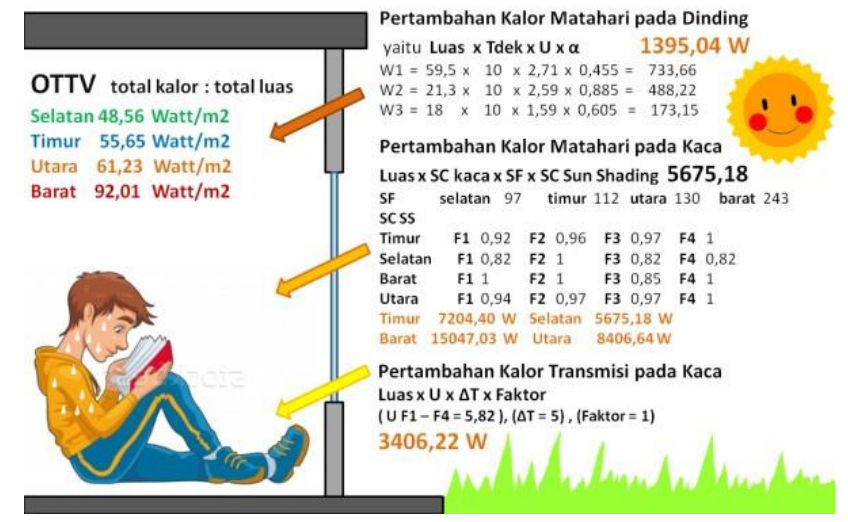

Gambar 9. OTTV Facade Selatan bila Disimulasikan Berbagai Orientasi

Tabel di bawah adalah beberapa rekomendasi kaca yang tepat dengan nilai OTTV maksimal 45 watt / m2 yang dipengaruhi juga oleh faktor harga.

\begin{tabular}{|l|l|c|c|}
\hline \multicolumn{2}{|c|}{ Kaca } & $\begin{array}{c}\text { SC } \\
\text { maks }\end{array}$ & \\
\hline Selatan & Kaca single & 0,48 & Kaca warna hijau \\
\hline & Kaca double & 0,66 & Kaca warna biru \\
\hline Timur & Kaca single & 0,38 & Kaca reflektif gelap \\
\hline & Kaca double & 0,52 & Kaca warna hijau \\
\hline Utara & Kaca single & 0,33 & Cool lite biru \\
\hline & Kaca double & 0,44 & Kaca reflektif hijau \\
\hline Barat & Kaca single & 0,18 & Cool lite silver \\
\hline & Kaca double & 0,25 & Cool lite biru \\
\hline
\end{tabular}

Tabel 2. Alternatif Jenis Kaca yang Tepat pada Facade Selatan untuk Berbagai Orientasi

\subsection{Facade Timur Disimulasikan dengan Menghilangkan Beton pada Double Skin}

Pada facade eksisting terdapat double skin pada selubungnya. Pada perhitungan Overall Thermal Transfer Value, double skin dianggap dinding tak tembus cahaya. Maka akan dilakukan percobaan apabila double skin diganti bahan kaca supaya tampilan lebih terlihat modern dengan tampilan full kaca dan percobaan tersebut berfungsi untuk mengetahui nilai Overall Thermal Transfer Value gedung full kaca untuk berbagai orientasi.

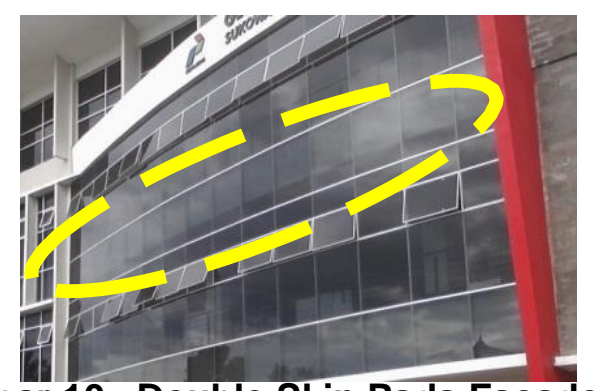

Gambar 10. Double Skin Pada Facade Timur

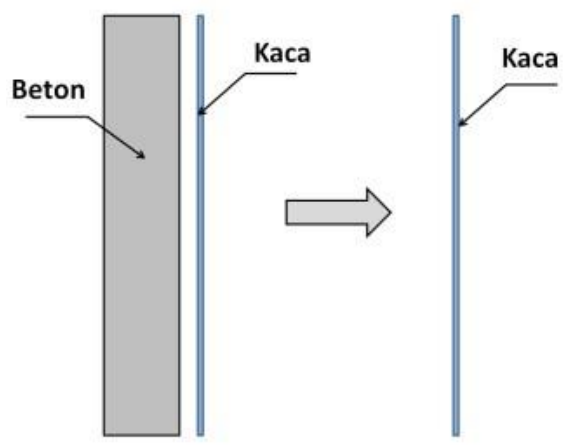

Gambar 11. Beton Pada Double Skin Dihilangkan

Pada facade ini dengan rasio kaca $77 \%$, apabila disimulasikan ke berbagai orientasi maka Overall Thermal Transfer Value ( OTTV ) urutan dari terkecil ke terbesar adalah Selatan, Timur, Utara, Barat. Nilai OTTV untuk semua orientasi di atas standard $45 \mathrm{Watt} / \mathrm{m} 2$, maka ruangan cenderung panas.

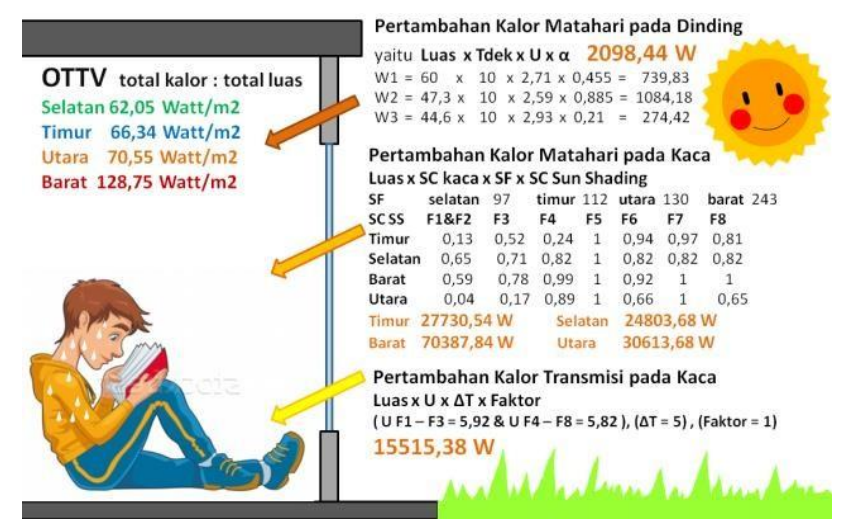

Gambar 12. OTTV Facade Timur untuk Berbagai Orientasi dengan Beton pada Double Skin Dihilangkan 
Tabel di bawah adalah beberapa rekomendasi kaca yang tepat dengan nilai OTTV maksimal 45 watt / $\mathrm{m} 2$ yang dipengaruhi juga oleh faktor harga.

\begin{tabular}{|l|l|c|c|}
\hline \multicolumn{2}{|l|}{ Kaca } & $\begin{array}{c}\text { SC } \\
\text { maks }\end{array}$ & Jenis kaca \\
\hline Timur & Kaca single & 0,26 & Cool lite biru \\
\hline & Kaca double & 0,42 & Kaca reflektif hijau \\
\hline Selatan & Kaca single & 0,29 & Cool lite biru \\
\hline & Kaca double & 0,48 & Kaca warna hijau \\
\hline Utara & Kaca single & 0,23 & Cool lite hijau \\
\hline Barat & Kaca double & 0,38 & Kaca reflektif gelap \\
\hline & Kaca double & 0,17 & Cool lite silver \\
\hline
\end{tabular}

Tabel 3. Alternatif Jenis Kaca yang Tepat pada Facade Timur untuk Berbagai Orientasi apabila Beton pada Double Skin Dihilangkan

\subsection{Facade Selatan Disimulasikan dengan Menghilangkan Beton pada Double Skin}

Pada facade selatan dengan rasio kaca $62 \%$, apabila disimulasikan ke berbagai orientasi maka Overall Thermal Transfer Value ( OTTV ) urutan dari terkecil ke terbesar adalah Selatan, Timur, Utara, Barat. Nilai OTTV untuk semua orientasi di atas standard $45 \mathrm{Watt} / \mathrm{m} 2$, maka ruangan cenderung panas.

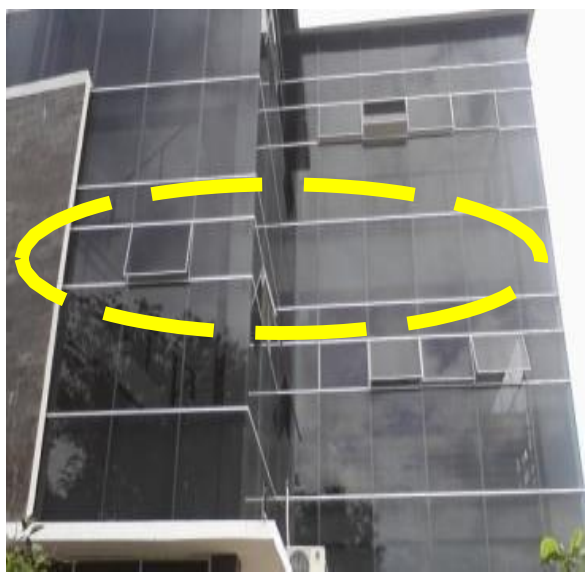

Gambar 13. Double Skin Pada Fasade Selatan

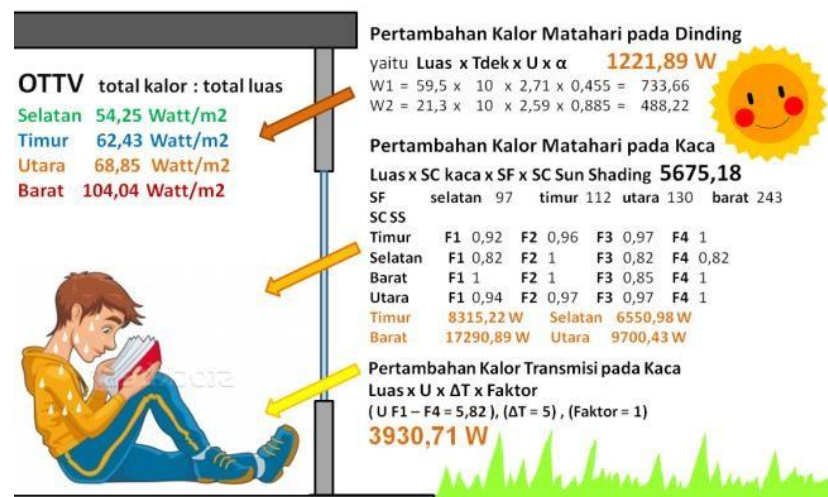

Gambar 14. OTTV Fasade Selatan untuk Berbagai Orientasi dengan Beton pada Double Skin Dihilangkan

Tabel di bawah adalah beberapa rekomendasi kaca yang tepat dengan nilai OTTV maksimal 45 watt / $\mathrm{m} 2$ yang dipengaruhi juga oleh faktor harga.

\begin{tabular}{|l|l|c|c|}
\hline \multicolumn{2}{|l|}{ Kaca } & $\begin{array}{c}\text { SC } \\
\text { maks }\end{array}$ & Jenis kaca \\
\hline Selatan & Kaca single & 0,38 & Kaca reflektif gelap \\
\hline & Kaca double & 0,56 & Kaca warna hijau \\
\hline Timur & Kaca single & 0,3 & Cool lite biru \\
\hline & Kaca double & 0,44 & Kaca reflektif hijau \\
\hline Utara & Kaca single & 0,26 & Cool lite biru \\
\hline Barat & Kaca double & 0,37 & Kaca reflektif gelap \\
\hline & Kaca single & 0,14 & Cool lite silver \\
\hline & Kaca double & 0,21 & Cool lite silver \\
\hline
\end{tabular}

Tabel 4. Alternatif Jenis Kaca yang Tepat pada Fasade Selatan untuk Berbagai Orientasi apabila Beton pada Double Skin Dihilangkan

\section{SIMPULAN}

Pada facade kaca gelap dengan rasio kaca lebih dari $50 \%$ memiliki nilai Overall Thermal Transfer Value melebihi standard 45 Watt / m2 untuk semua orientasi, maka ruangan cenderung panas. 
Urutan orientasi yang paling baik untuk fasade Gedung Sukowati adalah Selatan, Timur, Utara dan Barat.

Ruangan Gedung Sukowati cenderung panas dikarenakan dengan desain yang dominan kaca dan minim sun shading serta penggunaan jenis kaca yang kurang tepat. Dengan desain tersebut apabila menggunakan kaca warna atau panasap gelap, ruangan masih panas karena shading coefficient kaca panasap tinggi. Kaca yang tepat adalah cool lite pada orientasi timur.

Kaca berwarna gelap memiliki nilai shading coefficient lebih rendah daripada kaca warna biru, hijau dan pink. Namun penggunaan kaca yang tepat lebih ditentukan pada nilai shading coefficient kaca itu bukan pada warna. Misalnya, jenis kaca reflektif hijau memiliki nilai shading coefficient lebih rendah daripada kaca warna gelap ( abu - abu, biru gelap, abu - abu gelap )

Kaca yang tepat untuk gedung ini adalah kaca reflektif dan cool lite. Kaca reflektif dan cool lite harganya jauh lebih mahal dibanding kaca warna atau panasap yang digunakan pada Gedung Sukowati Semarang.

\section{REFERENSI}

ASHRAE. 1997. ASHRAE Fundamentals. Atlanta : American Society of Heating Refrigerating and Air Conditioning Engineers, Inc.

Badan Standardisasi Nasional. 2000. Konservasi Energi Selubung Bangunan. Jakarta

Egan,David. 1975 . Concepts In Thermal Comfort. New Jersey : Prentice Hall

Frick, Heinz \& Tri Hesti Mulyani. 2006. Asitektur Ekologis. Yogyakarta : Kanisius

Juniwati Santoso, Anik \& I Gusti Ngurah Antaryama. 2005 . Konsekuensi Energi Akibat Pemakaian Bidang Kaca pada Bangunan Tinggi di Daerah Tropis Lembab. Surabaya : Universitas Kristen Petra \& Institut Teknologi Sepuluh November

Lippsmeier,George. 1994. Bangunan Tropis. Jakarta : Erlangga

Loekito,Sandra. 2006. Analisis Konservasi Energi Melalui Selubung Bangunan. Surabaya : Universitas Kristen Petra

Priatman, Jimmy. 2003. Konsepsi dan Strategi Perancangan Bangunan di Indonesia. Surabaya : Universitas Kristen Petra
Schwolsky, Rick \& James I. Williams. 1982 . The Builder's Guide To Solar Construction. USA

Watson, Donald. 1993. The Energi Design Handbook. The American Institute of Architecs Press : New York 